\title{
The Role of Chitinase Production by Stenotrophomonas maltophilia Strain C3 in Biological Control of Bipolaris sorokiniana
}

\author{
Zhongge Zhang and Gary Y. Yuen
}

Department of Plant Pathology, University of Nebraska, Lincoln 68583-0722.

Current address of Z. Zhang: Department of Plant Pathology, University of Arizona, Tucson 85721.

Accepted for publication 21 December 1999.

\begin{abstract}
Zhang, Z., and Yuen, G. Y. 2000. The role of chitinase production by Stenotrophomonas maltophilia strain C3 in biological control of Bipolaris sorokiniana. Phytopathology 90:384-389.

The role of chitinase production by Stenotrophomonas maltophilia strain C3 in biological control of leaf spot on tall fescue (Festuca arundinacea), caused by Bipolaris sorokiniana, was investigated in vitro and in vivo. The filtrate of a broth culture of $\mathrm{C} 3$, with chitin as the carbon source, was separated into fractions. A high molecular-weight fraction $(>8 \mathrm{kDa}$ ) was chitinolytic and more inhibitory than a low-molecularweight, nonchitinolytic fraction to conidial germination and hyphal growth by $B$. sorokiniana and to leaf spot development. A protein fraction derived by ammonium sulfate precipitation and a chitinase fraction purified by chitin affinity chromatography also were chitinolytic and highly antifungal. The chitinolytic fractions caused swelling and vacuolation of conidia and discoloration, malformation, and degradation of germ tubes. When boiled, the chitinolytic fractions lost chitinase activity along with
\end{abstract}

ABSTRACT most of the antifungal properties. Two chitinase-deficient and two chitinase-reduced mutants of $\mathrm{C} 3$ were compared with the wild-type strain for inhibition of germination of $B$. sorokiniana conidia on tall fescue leaves and for suppression of leaf spot development in vivo. The mutants exhibited reduced antifungal activity and biocontrol efficacy, but did not lose all biocontrol activity. An aqueous extract of leaves colonized by wild-type C3 had higher chitinase activity than that of noncolonized leaves and was inhibitory to conidial germination. The addition of chitin to leaves along with the wild-type strain increased both chitinase and antifungal activity. The chitinase activity level of extracts from leaves colonized by a chitinase-deficient mutant of $\mathrm{C} 3$, with and without added chitin, was no higher than the background, and the extracts lacked antifungal activity. Chitinolysis appears to be one mechanism of biological control by strain $\mathrm{C} 3$, and it functions in concert with other mechanisms.

Additional keywords: antagonism, antibiosis, microbial interactions, turf grass.
Stenotrophomonas maltophilia strain C3 was selected originally as an antagonist of Rhizoctonia solani AG 1-IA, causal agent of brown patch disease in turf grass (6). In growth-chamber and field experiments on tall fescue (Festuca arundinacea Schreb.), the bacterial strain suppressed leaf spot caused by Bipolaris sorokiniana (Sacc.) Shoemaker (teleomorph Cochliobolus sativus (Ito \& Kuribayashi) Drechs. ex Dastur) (32). Strain C3 is chitinolytic, a trait common in Stenotrophomonas maltophilia (19). When chitin was added to cell suspensions of C3 applied to tall fescue leaves, inhibition of pathogen conidial germination and suppression of symptom development by the bacterium was enhanced (32). Although other studies have shown that the addition of chitin to foliage or soil can increase numbers of chitinolytic microorganisms $(11,22)$, chitin did not affect phylloplane colonization by strain C3. Chitinase production in other bacterial species, such as Serratia marcescens (16), was reported to be induced in the presence of chitin-containing substrates, raising the possibility that chitin amendments served to induce chitinase production by $\mathrm{C} 3$ on leaf surfaces.

Enzymatic lysis of fungal cell walls through extracellular chitinases has been implicated as one mechanism of biocontrol by bacterial agents, including rhizosphere strains of Stenotrophomonas maltophilia $(8,9)$, but chitinolysis has not been reported in connection with inhibition of fungi by Stenotrophomonas maltophilia in the phyllosphere. The primary approaches used to investigate the role of chitinase in plant disease biological control

Corresponding author: G. Y. Yuen; E-mail address: gyuen1@unl.edu

Publication no. P-2000-0210-01R

(c) 2000 The American Phytopathological Society have been to evaluate the effects of chitinases produced in vitro, to inactivate native chitinase-encoding genes in the biocontrol agent, and to express exogenous chitinase genes in other agents. For example, a chitinase partially purified from a culture of Escherichia coli transformed with a chitinase gene from Serratia marcescens inhibited diseases caused by Sclerotium rolfsii in bean and $R$. solani in cotton (24). The importance of chitinase produced by Serratia marcescens was further demonstrated by expressing chitinase genes from Serratia marcescens in a strain of Pseudomonas fluorescens, conferring to the recipient the ability to control $\mathrm{Fu}$ sarium oxysporum $\mathrm{f}$. sp. redolens in radish (26) and $R$. solani in cotton (10). As an example of results derived from mutational analysis, a chitinase-deficient mutant of Enterobacter agglomerans was less effective than the wild-type strain in protecting cotton against $R$. solani (4). Few studies exist in which levels of chitinase produced by microorganisms in vivo were determined. RodriguezKabana et al. (22) found that an increase in the population level of chitinolytic microbes upon addition of chitin to soil was associated with increased chitinase activity as measured by the release of $\mathrm{N}$-acetylglucosamine. Chitinase production by applied biocontrol agents on plant tissues has not been demonstrated by direct detection or quantification.

The objective of this study was to determine the relationship between chitinolysis and antagonism by strain $\mathrm{C} 3$ against $B$. sorokiniana. Two approaches were used, the first being the evaluation of chitinolytic factors excreted by strain $\mathrm{C} 3$ in vitro for effects on pathogen growth and disease development, and the second being a comparison between wild-type $\mathrm{C} 3$ and chitinase-deficient mutants with respect to chitinase production and pathogen inhibition in vivo. Preliminary reports have been published (29-31). 


\section{MATERIALS AND METHODS}

General microbial and plant-culturing methods. Strain C3 and its derivatives were stored at $-70^{\circ} \mathrm{C}$ in nutrient broth containing $10 \%$ glycerol. For each experiment, a fresh culture of a strain was grown on tryptic soy agar (TSA; Sigma Chemical Co., St. Louis) for $24 \mathrm{~h}$ at $25^{\circ} \mathrm{C}$. Cells were suspended in sterile $0.01 \mathrm{M}$ potassium phosphate buffer, $\mathrm{pH}$ 7.0, and the suspension was used for inoculating broth cultures and plant materials. Cell density in every suspension was adjusted to $10^{9} \mathrm{CFU} / \mathrm{ml}$ by measuring turbidity in a spectrophotometer (Spectronic 20, Spectronic Instruments, Inc., Rochester, NY) and diluting with sterile phosphate buffer to the desired concentration. A spontaneous rifampicin derivative of strain C3 (6) was used in all experiments. Its population size was determined by dilution plating on TSA amended with rifampicin (Sigma) at $100 \mu \mathrm{g} / \mathrm{ml}$.

B. sorokiniana, isolated in Nebraska from Kentucky bluegrass (Poa pratensis), was used for spore germination experiments and plant inoculations. Culturing conditions and procedures for producing inoculum in the form of conidial suspensions were described previously (32).

Tall fescue cv. Kentucky-31 was used in experiments on in vivo chitinase production and antagonism by bacterial strains. Seeds were planted in a steam-pasteurized potting medium (Sharpsburg siltyclay loam, vermiculite, and sand mixed in equal volumes) contained in $15-\mathrm{cm}$ pots ( 200 seeds per pot). The plants were grown for over 45 days in a greenhouse under natural light at an average temperature of $25^{\circ} \mathrm{C}$ and watered daily with a nutrient solution (Peters 20-10-20, Scotts-Sierra Horticultural Co., Marysville, OH) containing $\mathrm{N}$ at $0.2 \mathrm{~g} / \mathrm{liter}$. Plants were cut to a height of $5 \mathrm{~cm}$ every 10 days.

Preparation of culture filtrate fractions. For experiments on chitinase production in vitro, strain $\mathrm{C} 3$ was cultured in a broth medium containing $\left(\mathrm{NH}_{4}\right)_{2} \mathrm{SO}_{4}$ at $1.0 \mathrm{~g} /$ liter, $\mathrm{MgSO}_{4} \cdot 7 \mathrm{H}_{2} \mathrm{O}$ at $0.3 \mathrm{~g} / \mathrm{liter}$, and $\mathrm{KH}_{2} \mathrm{PO}_{4}$ at $1.36 \mathrm{~g} /$ liter (16). Colloidal chitin, prepared from practical-grade chitin (Sigma) by the method of Roberts and Selintrennikoff (20), was added to $5 \mathrm{~g} / \mathrm{liter}$ as a carbon source. Yeast extract (Sigma) was autoclaved separately and added to sterilized broth to $0.5 \mathrm{~g} / \mathrm{liter}$. Four replicate cultures (50-ml volumes in 250-ml Erlenmeyer flasks) were incubated for 5 days at $25^{\circ} \mathrm{C}$ with shaking (180 rpm; Radial Shaker model 4710, Queue Systems, Parkersburg, WV), and centrifuged (J2-21, Beckman Instruments, Inc., Palo Alto, CA) at $15,000 \times g$ for 20 min to remove cells and debris. The supernatants were sterilized by filtration through $0.22-\mu \mathrm{m}$ cellulose nitrate membranes (Nalge Nunc International, Rochester, NY) and pooled. Portions of the filtrate were separated into low and high molecular-weight fractions by overnight ultrafiltration through a YM-10 membrane (Amicon, Beverly, MA), with a cutoff of $8,000 \mathrm{Da}$, at $4^{\circ} \mathrm{C}$. A protein fraction was prepared separately by dissolving $\left(\mathrm{NH}_{4}\right)_{2} \mathrm{SO}_{4}$ in a portion of the raw filtrate to $85 \%$ saturation and incubating with stirring at $4^{\circ} \mathrm{C}$ for $4 \mathrm{~h}$. Precipitated proteins were collected by centrifugation at $20,000 \times g$ for $20 \mathrm{~min}$. The protein pellet was dissolved in phosphate buffer and dialyzed against the same buffer. Each of the fractions was adjusted to its original volume with phosphate buffer. To test the fractions for sensitivity to heat, 1-ml aliquots were boiled for $10 \mathrm{~min}$ and immediately cooled in ice water to $4^{\circ} \mathrm{C}$. All culture fluid fractions were stored at $-20^{\circ} \mathrm{C}$ prior to use.

In a separate set of experiments, a partially purified chitinase fraction was prepared by chitin affinity chromatography. All steps were performed at $4^{\circ} \mathrm{C}$ unless otherwise noted. A column $(15 \times$ $2.5 \mathrm{~cm}$ ) packed with regenerated chitin, prepared by the method of Molano et al. (15), was equilibrated with $20 \mathrm{mM} \mathrm{NaHCO}_{3}(\mathrm{pH} \mathrm{8.4)}$. Proteins were collected from a chitin broth culture of $\mathrm{C} 3$ by ammonium sulfate precipitation as described above. The protein pellet was dissolved in a minimum volume of $20 \mathrm{mM}$ sodium bicarbonate buffer ( $\mathrm{pH} \mathrm{8.4)} \mathrm{and} \mathrm{dialyzed} \mathrm{against} \mathrm{the} \mathrm{same} \mathrm{buffer.} \mathrm{An} \mathrm{8-ml}$ volume of the dialyzed protein preparation was loaded into the column. After incubation on ice for $1 \mathrm{~h}$, the column was washed with $300 \mathrm{ml}$ of sodium bicarbonate buffer followed by $200 \mathrm{ml}$ of $20 \mathrm{mM}$ sodium acetate ( $\mathrm{pH}$ 5.5) to remove components binding nonspecifically to the chitin. Chitinases were eluted by washing the column with $300 \mathrm{ml}$ of $20 \mathrm{mM}$ acetic acid (pH 3.0). The aceticacid fraction was collected, concentrated to $\approx 10 \mathrm{ml}$ in a stirred pressure cell over a YM-10 membrane, dialyzed against $10 \mathrm{mM}$ sodium acetate $(\mathrm{pH} 5.5)$, and stored at $-20^{\circ} \mathrm{C}$. In experiments comparing the partially purified chitinase fraction with the raw culture filtrate for antifungal activity, fluids were standardized to $0.25 \mathrm{mg}$ of protein per $\mathrm{ml}$, with protein content determined by the Bradford method (2), using bovine serum albumin as a standard.

Derivation of chitinase mutants. Spontaneous mutant strains of $\mathrm{C} 3$ altered in chitinase activity were selected from colonies of C3 growing on Luria-Bertani agar (Sigma) containing rifampicin and chloramphenicol at $100 \mu \mathrm{g} / \mathrm{ml}$ each. Strains that produced small or no hydrolytic zones when cultured for 3 days on TSA amended with $0.2 \%$ colloidal chitin were purified and repeatedly tested for colony morphology, growth rate, chloramphenicol resistance, and chitinolysis in comparison with wild-type strain C3. Four mutant strains were compared with the wild-type for production of $\beta-1,3-$ glucanase, lipase, and protease using methods described below. In addition, they were evaluated for production of antibacterial factors on the basis of a plate inhibition test against Clavibacter michiganensis subsp. nebraskensis and Pseudomonas syringae pv. tomato.

Preparation of extracts from grass leaves. To determine chitinase production on grass leaves by wild-type strain $\mathrm{C} 3$ and its mutants, cell suspensions containing $10^{8} \mathrm{CFU} / \mathrm{ml}$ in phosphate buffer were applied to pots of tall fescue plants until runoff with a hand-pumped sprayer (RL Flo-Master, Wal-Mart Stores, Inc., Bentonville, AR). Cell suspensions amended with $0.25 \%$ colloidal chitin were applied to another set of plants. The controls included plants treated with chitin in phosphate buffer or with phosphate buffer alone. For each treatment, there were four replicate pots, and all pots were arranged in a completely randomized design in a growth chamber. A 12-h photoperiod was provided, consisting of 60 to $73 \%$ relative humidity and $25^{\circ} \mathrm{C}$ during the light period and $>93 \%$ relative humidity and $18^{\circ} \mathrm{C}$ during the dark period. High moisture was provided by an ultrasonic humidifier (model 696, Sunbeam Products, Inc., Boca Raton, FL) that was operated intermittently. On days 0 and $4,1 \mathrm{~g}$ of leaves was collected from each pot into sterile tubes and washed with $2 \mathrm{ml}$ of potassium phosphate buffer. A portion of each wash was used in determining population sizes of the applied strain. The remainder of the wash was centrifuged $(15,000 \times g, 20 \mathrm{~min})$, and the supernatant was filtered through $0.22-\mu \mathrm{m}$ membranes. The filtrates were stored at $-20^{\circ} \mathrm{C}$ before being assayed for chitinase activity and antifungal properties. The washed leaves were dried at $60^{\circ} \mathrm{C}$ for 3 days and weighed so chitinase and population-size measurements could be expressed on a sample dry weight basis.

Enzyme activity assays. Chitinase production by bacterial strains in culture was detected by streaking or spotting strains on TSA amended with $0.2 \%$ colloidal chitin. The cultures were incubated at $25^{\circ} \mathrm{C}$ and examined periodically for clear zones of hydrolysis around colonies. Chitinase activity in cell-free liquids was assessed by two methods. In one method, $50-\mu 1$ aliquots were pipetted into wells $(0.4 \mathrm{~cm}$ diameter) made in water agar containing $0.2 \%$ colloidal chitin. The plates were examined for the clarity, shape, and size of hydrolytic zones after 3 days of incubation at $25^{\circ} \mathrm{C}$. In the other method, chitinolysis was measured through the hydrolysis of $p$-nitrophenyl- $N, N^{\prime}$-diacetylchitobiose (Sigma), releasing $p$-nitrophenol as a yellow product $(20)$. Aliquots $(10 \mu \mathrm{l})$ of test fluids were added to $60 \mu \mathrm{l}$ of $0.2 \mathrm{mM}$-nitrophenyl reagent in $50 \mathrm{mM}$ potassium phosphate buffer, $\mathrm{pH} 6.0$, in duplicate wells of a microplate. After the mixture was incubated at $37^{\circ} \mathrm{C}$ for $30 \mathrm{~min}$, the reaction was terminated by adding $10 \mu \mathrm{l}$ of $1 \mathrm{~N} \mathrm{NaOH}$ to each well. The amount of $p$-nitrophenol produced was determined by measuring the absorbance of the fluids at $405 \mathrm{~nm}$ with an Optimax Microplate Reader (Molecular Devices Corp., Sunnyvale, CA). The 
absorbance values were converted to nanomoles of $p$-nitrophenol according to a standard curve of $p$-nitrophenol at known concentrations versus absorbance at $405 \mathrm{~nm}$. One unit of enzyme activity was defined as the amount of enzyme that produced $1 \mathrm{nmol}$ $p$-nitrophenol per min at $37^{\circ} \mathrm{C}$.

$\beta-1,3-$ Glucanase activity was determined by the procedure described by Zheng and Wosniak (34), using laminarin as the substrate. Protease activity was determined by a method reported by Whooley et al. (27), using casein as the substrate. Lipase activity was estimated by a plate assay described by Smeltzer et al. (25) with triolein (Sigma) as the substrate.

Antifungal bioassays. C3 culture fluid fractions and extracts from bacteria-colonized tall fescue leaves were tested for their effects on spore germination and hyphal growth of $B$. sorokiniana. In spore germination tests, $40 \mu \mathrm{l}$ of test fluid was mixed with an equal volume of conidial suspension in the well of a sterile depression slide. The slide was incubated at room temperature for $20 \mathrm{~h}$ in a petri dish lined with moist filter paper. At least 100 conidia were examined for germination using an Optiphot Compound Microscope (Nikon Inc., Melville, NY) at a magnification of $\times 410$. Length of each germ tube from germinated conidia was measured with an ocular micrometer.

In experiments for evaluating the effects of culture fluids or bacterial strains on Bipolaris leaf spot development, cell suspen- sions or test fluids were sprayed on tall fescue plants in pots, with four pots for each treatment. One day later, a B. sorokiniana conidial suspension was sprayed on all of the turf foliage. Pots of plants treated with conidia alone served as the nontreated, inoculated control. Throughout the experiment, the pots were maintained in a growth chamber with fluctuating conditions as described above. At 1 day after inoculation with the pathogen, leaves were sampled from each pot and examined microscopically for conidial germination using methods described by Zhang and Yuen (32). At 4 and 8 days after pathogen inoculation, 10 leaf blades were collected from each pot. The infection frequency in each sample from day 4 was determined by dividing the total number of lesions by the total linear length of leaf blades in the sample. The disease severity in each sample collected on day 8 was assessed by estimating percent leaf area exhibiting lesions and chlorosis. At various intervals during each experiment, samples of leaves were collected from each pot to evaluate population sizes of applied bacterial strains. Samples were placed in plastic bags with zip-locking enclosures and washed with a set volume of phosphate buffer. The wash was used in dilution plating.

Statistical analysis. All experiments described above were repeated. Pooled analysis of variance was used to analyze data from the two repetitions together. Bacterial population numbers were converted to $\log _{10}$ (colony forming units +1 ) prior to analysis.

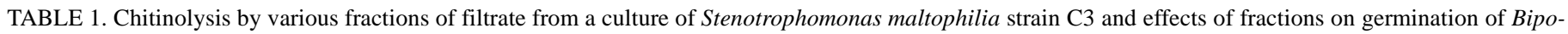
laris sorokiniana conidia in vitro and development of leaf spot on tall fescue ${ }^{\mathrm{u}}$

\begin{tabular}{|c|c|c|c|c|c|}
\hline Filtrate fraction ${ }^{\mathrm{v}}$ & Heat treatment ${ }^{\mathrm{w}}$ & Chitinolysis $^{\mathrm{x}}$ & Germination $(\%)^{\mathrm{y}}$ & Lesions $/ 10 \mathrm{~cm}$ of leaf ${ }^{2}$ & Diseased leaf area $(\%)^{\mathrm{y}}$ \\
\hline Whole filtrate & - & + & $8 \mathrm{~d}$ & $0 \mathrm{~d}$ & $1 \mathrm{~d}$ \\
\hline Whole filtrate & + & - & $58 \mathrm{c}$ & NT & NT \\
\hline Protein fraction & - & + & $9 \mathrm{~d}$ & $16 \mathrm{c}$ & $9 \mathrm{c}$ \\
\hline Protein fraction & + & - & $51 \mathrm{c}$ & $31 \mathrm{a}$ & $33 \mathrm{~b}$ \\
\hline High molecular-weight fraction & - & + & $9 \mathrm{~d}$ & $1 \mathrm{~d}$ & $2 d$ \\
\hline High molecular-weight fraction & + & - & $53 \mathrm{c}$ & $10 \mathrm{c}$ & $10 \mathrm{c}$ \\
\hline Low molecular-weight fraction & - & - & $80 \mathrm{~b}$ & $24 \mathrm{~b}$ & $28 \mathrm{~b}$ \\
\hline Phosphate buffer control & - & - & $92 \mathrm{a}$ & $36 \mathrm{a}$ & $41 \mathrm{a}$ \\
\hline
\end{tabular}

u Values in a column followed by the same letter are not significantly different $(P=0.01)$ according to Duncan's multiple range test; NT $=$ not tested.

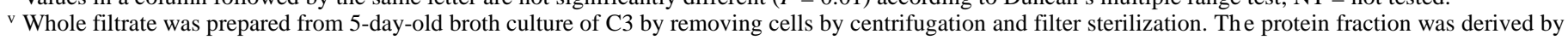
ammonium sulfate precipitation and dissolution in phosphate buffer. Low and high molecular-weight factions were prepared from whole filtrate by ultrafiltration through a 8,000-Da membrane.

${ }^{\mathrm{w}}$ Filtrate fractions were boiled for $10 \mathrm{~min}$.

$\mathrm{x}+$ and - indicate presence and absence, respectively, of clear hydrolysis zones on water agar containing colloidal chitin.

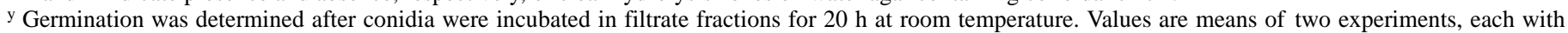
four replications per treatment.

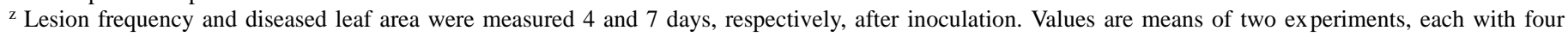
replications per treatment.
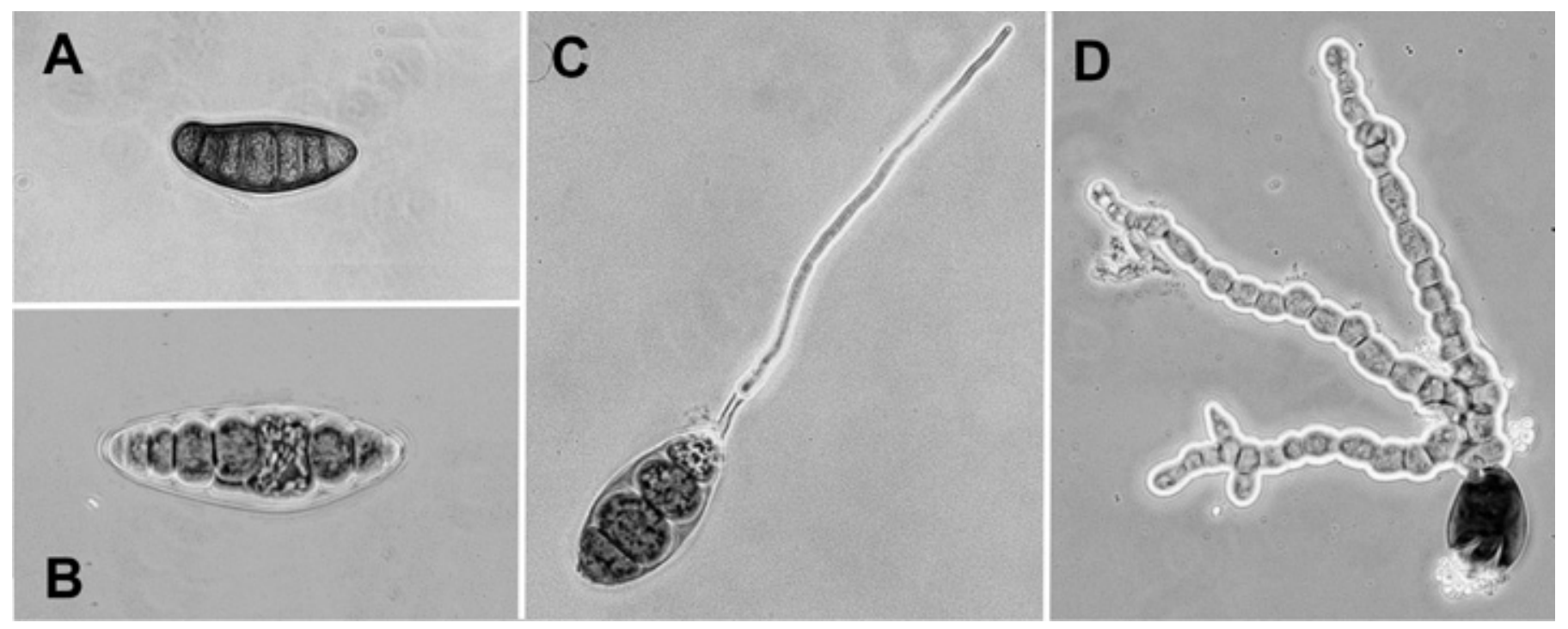

Fig. 1. Nongerminated and germinated conidia of Bipolaris sorokiniana after $20 \mathrm{~h}$ of incubation in A and C, phosphate buffer and B and D, high molecularweight fraction of a filtrate from a culture of Stenotrophomonas maltophilia strain C3. All images were photographed at 410x. 
Fisher's least significant difference (LSD) and Duncan's multiple range tests were used for mean separation. Percentage data (i.e., conidial germination and disease severity) were analyzed with and without arcsine transformation, but only results involving nontransformed data are reported because the transformation did not affect the statistical analysis.

\section{RESULTS}

Effects of $\mathrm{C} 3$ culture filtrate fractions on $\boldsymbol{B}$. sorokiniana in vitro. The raw culture fluid and the high molecular-weight and protein fractions of the culture fluid were chitinolytic, producing clear hydrolytic zones when they were applied to water agar containing chitin (Table 1). Boiling these fluids for $10 \mathrm{~min}$ resulted in loss of chitinase activity. The high molecular-weight and protein fractions were as inhibitory to germination of B. sorokiniana conidia as the raw culture filtrate. Heating of these fractions significantly reduced, but did not completely eliminate, their inhibitory properties. The low molecular-weight fraction was not chitinolytic and only slightly inhibitory to spore germination.

B. sorokiniana conidia that failed to germinate after exposure to the high molecular-weight or protein fractions appeared swollen and vacuolated. In some of the treated conidia that did germinate, the germ tubes stopped growing before their lengths equaled the width of the spores. In others, the hyphae exhibited swelling of the tips, highly irregular branching, and pronounced cell alterations, such as swelling, browning, and shortening, compared with hyphae in the nontreated controls (Fig. 1). The low molecular-weight fraction did not have these effects on the conidia or hyphal development (data not shown).

Effects of $\mathrm{C} 3$ culture fractions on Bipolaris leaf spot disease. When applied to tall fescue plants, the culture filtrate and all the fractions in nonheated form suppressed leaf spot disease compared

TABLE 2. Effects of filtrates of a culture of Stenotrophomonas maltophilia strain $\mathrm{C} 3$ and a chitinase fraction derived by chitin affinity chromatography on conidial germination and germ tube elongation by Bipolaris sorokiniana ${ }^{\mathrm{w}}$

\begin{tabular}{lccc}
\hline Treatment & $\begin{array}{c}\text { Chitinase } \\
\text { activity }^{\mathrm{x}}\end{array}$ & $\begin{array}{c}\text { Germination } \\
(\%)^{\mathrm{y}}\end{array}$ & $\begin{array}{c}\text { Germ tube } \\
\text { length }(\mu \mathrm{m})^{\mathrm{y}}\end{array}$ \\
\hline Raw culture filtrate & 0.14 & $10 \mathrm{c}$ & $2 \mathrm{c}$ \\
Chitinase fraction $^{\mathrm{z}}$ & 1.21 & $30 \mathrm{~b}$ & $8 \mathrm{~b}$ \\
Phosphate buffer & 0.00 & $81 \mathrm{a}$ & $19 \mathrm{a}$ \\
\hline
\end{tabular}

${ }^{w}$ Values in a column followed by the same letter are not significantly different $(P=0.01)$ according to a least significant difference test.

${ }^{x}$ Chitinase activity was measured in units per milligram of protein by hydrolysis of $p$-nitrophenyl- $N, N^{\prime}$-diacetylchitobiose.

y Germination was determined after conidia were incubated in culture fluid fractions or phosphate buffer for $20 \mathrm{~h}$ at room temperature. Each fraction was adjusted to a protein concentration of $0.25 \mathrm{mg} / \mathrm{ml}$ prior to antifungal assay. Values are means of four replications.

${ }^{\mathrm{z}}$ Fraction eluted from chitin affinity chromatography column by $20 \mathrm{mM}$ acetic acid (pH 3.0) and adjusted to $\mathrm{pH} 5.5$. with the control (Table 1). Only the high molecular-weight fraction reduced lesion frequency, measured on day 4 , to the same extent as the whole filtrate. Both the high molecular-weight fraction and the protein fraction were similar to the whole filtrate in reducing disease severity by day 8 . Lesion frequency and disease severity on plants treated with the low molecular-weight fraction were significantly higher than with the other two fractions. When boiled for $10 \mathrm{~min}$, the protein and high molecular-weight fractions lost some, but not all, of their inhibitory capacity, because lesion frequency and disease severity levels in the treatments with boiled fractions were significantly lower than in the control.

The culture fluid fraction that was eluted from a chitin affinity column by acetic acid was highly chitinolytic, with nearly a 10 -fold increase in specific activity compared with the raw culture fluid. That fraction inhibited $B$. sorokiniana conidial germination and germ tube elongation compared with the phosphate buffer control (Table 2). However, it was less inhibitory to $B$. sorokiniana than the raw culture fluid at the same protein concentration.

Disease suppression and leaf colonization by chitinase-altered mutants. Of the 6,000 chloramphenicol-resistant derivatives tested for chitinolysis on colloidal chitin-amended TSA, 6 did not produce hydrolysis zones, and 42 formed smaller clearing zones than the wild-type strain. Two strains lacking any detectable chitinase activity (1-53 and 7-41) and two with reduced chitinase activity (20-14 and 24-8) were selected for further investigation because they were similar to the wild-type strain in growth rate and colony morphology. Chloramphenicol resistance and altered chitinase activity were stable in the mutant strains through repeated transfers. All four mutant strains were reduced in lipase activity, and three were reduced in $\beta-1,3$ glucanase activity compared with the wildtype (Table 3). Protease production in the mutant strains was unaffected, and antagonism against other bacteria was unchanged or increased.

When applied to tall fescue plants, all of the mutants inhibited stages of Bipolaris leaf spot disease development compared with the phosphate control (Table 3), but none were as effective as the wild-type strain. Although the spore germination levels varied among the four mutant strains, with the chitinase-reduced strain 20-14 having the lowest, there was no difference in disease inhibition between the strains deficient in chitinase activity and those reduced in chitinase activity. The mutants, in general, did not colonize tall fescue leaves over the long term to the same level as the wildtype. In one experiment, population sizes of three mutants were $\approx 1 \log$ unit lower than the wild-type (Fig. 2). Similar results were obtained in the repetition of the experiment (data not shown).

Chitinase production and antifungal activity on leaves. A chitinase-deficient mutant, 7-41, was compared with the wild-type for chitinase production in vivo. Significantly higher amounts of chitinase activity were detected in extracts of tall fescue leaves colonized for 4 days by strain $\mathrm{C} 3$ than in extracts of leaves without C3 (Table 4). The application of colloidal chitin with C3 fur-

TABLE 3. Comparison of wild-type and chitinase-deficient mutants of Stenotrophomonas maltophilia strain C3 for lytic enzyme activity, bacterial antagonism, and effects on germination of conidia of Bipolaris sorokiniana and development of leaf spot on tall fescue ${ }^{\mathrm{x}}$

\begin{tabular}{|c|c|c|c|c|c|c|c|c|}
\hline Strain & Chitinase & $\beta$-1,3-glucanase & Lipase & Protease & Bacterial antagonism ${ }^{y}$ & $\begin{array}{c}\text { Germination } \\
(\%)^{\mathrm{z}}\end{array}$ & $\begin{array}{c}\text { Lesions } / 10 \mathrm{~cm} \\
\text { of leaf }^{\mathrm{z}}\end{array}$ & $\begin{array}{l}\text { Diseased leaf } \\
\text { area }(\%)^{\mathrm{z}}\end{array}$ \\
\hline $\mathrm{C} 3$ & ++ & ++ & ++ & ++ & ++ & $11 \mathrm{~d}$ & $10 \mathrm{c}$ & $2 \mathrm{c}$ \\
\hline $1-53$ & - & ++ & + & ++ & ++ & $79 \mathrm{~b}$ & $41 b$ & $22 b$ \\
\hline $7-41$ & - & + & + & ++ & ++ & $86 \mathrm{a}$ & $36 \mathrm{~b}$ & $20 \mathrm{~b}$ \\
\hline $20-14$ & + & + & + & ++ & ++ & $68 \mathrm{c}$ & $33 \mathrm{~b}$ & $19 \mathrm{~b}$ \\
\hline $24-8$ & + & + & + & ++ & +++ & $81 \mathrm{~b}$ & $38 \mathrm{~b}$ & $25 \mathrm{~b}$ \\
\hline None & - & - & - & - & - & $87 \mathrm{a}$ & $52 \mathrm{a}$ & $38 \mathrm{a}$ \\
\hline
\end{tabular}

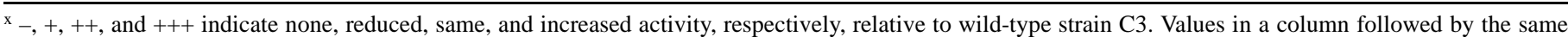
letter are not significantly different at $P=0.05$ for germination and $P=0.01$ for leasion frequency and diseased leaf area, according to Duncan's multiple range test.

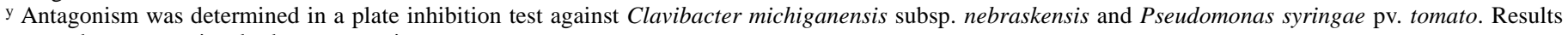
were the same against both target species.

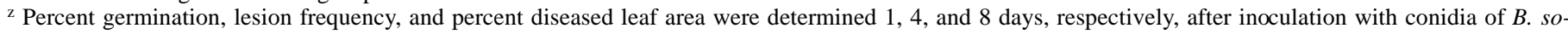
rokiniana. All values are means of two experiments, each with four replications per treatment. 
ther increased chitinase activity. The presence of strain 7-41 on leaves, with or without chitin, did not affect chitinase activity levels when compared with the respective no-bacteria controls.

The population density of wild-type $\mathrm{C} 3$ measured in the leaf extract was significantly higher than that of the chitinase-deficient mutant (Table 4). This reflected the population size of the wildtype on grass leaves increasing by $0.5 \mathrm{log}$ units, while that of 7-41 remained unchanged from the starting level over the 4-day experiment period. Neither strain was affected in colonization by addition of chitin.

The antifungal activity of the various leaf extracts, measured on the basis of their effect on germination of B. sorokiniana conidia, was related to the relative levels of chitinase activity (Table 4). Extracts from leaves colonized by 7-41 were the same as the controls in allowing high levels of conidial germination. Extracts from C3-colonized leaves, with and without chitin, significantly inhibited germination, with the chitin amendment producing the highest degree of inhibition.

\section{DISCUSSION}

We conclude that chitinolysis is one mechanism involved in the biological control of $B$. sorokiniana by strain $\mathrm{C} 3$. One line of evidence is the close association observed between chitinolytic factors produced by $\mathrm{C} 3$ in vitro and inhibition of spore germination and disease development. The major components in culture fluids active in fungal inhibition and disease suppression appeared to be heat-labile proteins rather than antibiotic compounds of low molecular weight. The observed alteration of germ tube and hyphal morphology by the chitinolytic high molecular-weight and protein fractions also support the hypothesis that chitinase was involved. Swelling, browning, branching, and degradation of germ tubes were reported as symptoms in fungi exposed to chitinase or chitinolytic microorganisms $(1,14,18)$. Kritizman et al. (12) showed that the active sites for chitinases are the tips, septa, and branches of hyphae.

As supportive evidence that chitinolysis is involved in antagonism by $\mathrm{C} 3$, chitinase-deficient and -reduced mutants of $\mathrm{C} 3$ were less disease suppressive than the wild-type. The mutants strains exhibited reduced colonization ability over the long term compared with the wild-type strain. However, pathogen inoculation was performed 1 day after bacterial treatment; therefore, the difference in population numbers at inoculation was small and could not account entirely for the large reduction in antifungal activity and disease suppressiveness observed in the mutants. Extracellular enzyme activity in strain C3 was globally regulated (D. Kobayashi,

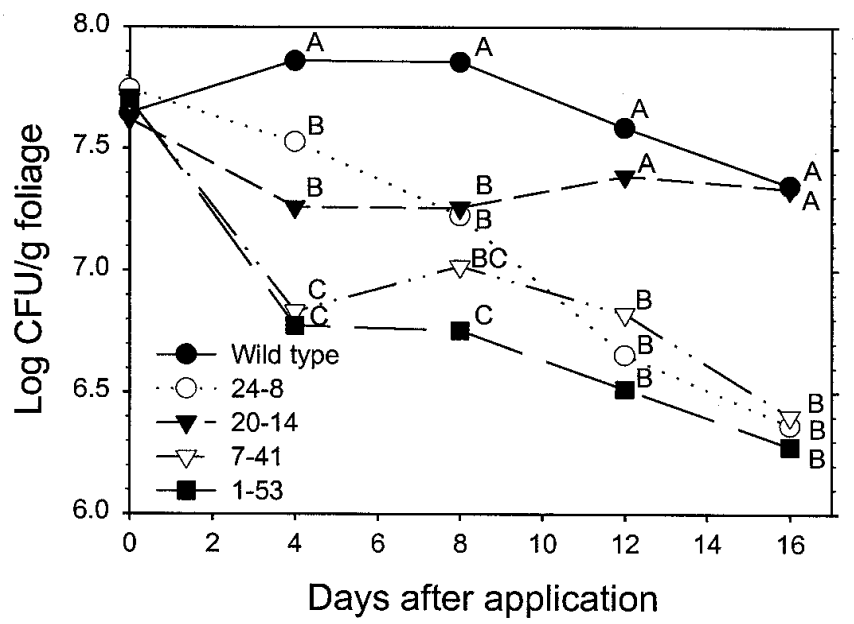

Fig. 2. Population sizes of Stenotrophomonas maltophilia wild-type strain C3 and chitinase-altered mutants on tall fescue in a growth chamber. Values on each time point followed by a common letter do not differ significantly $(P=$ 0.05 ) according to Duncan's multiple range test. personal communication); we suspect that global regulator sites were affected in mutants because they also had reduced $\beta$-glucanase and lipase activity. Furthermore, strain C3 produced multiple chitinases in a preliminary study (33); thus, it was unlikely that the mutations in the chitinase-deficient strains involved structural genes. We isolated the mutants from a chloramphenicol-amended medium in the process of generating transposon mutants. Although it is not clear what the connection between selection for antibiotic resistance and mutation in global control sites is, spontaneous gac regulatory mutants in $P$. aureofaciens and $P$. fluorescens were isolated under similar circumstances $(3,13)$.

Strong evidence for the importance of chitinase production by strain C3 is the detection of chitinase activity in extracts derived from $\mathrm{C} 3$-colonized leaves at levels that were well above that in noncolonized leaves. Furthermore, the extracts from C3-colonized leaves were antifungal, indicating that chitinase produced on leaves was sufficient in concentration to have a biological effect. The finding that colonization by a chitinase-deficient mutant did not result in chitinase levels above the background strongly supports the hypothesis that strain $\mathrm{C} 3$ produced chitinases on leaf surfaces, but we cannot rule out the possibility that the chitinase might also have been of plant origin. Roby et al. (21) reported that soluble oligomeric products of chitin hydrolysis, rather than insoluble polymers of chitin, induced plant defense proteins such as chitinases and, thus, the highly elevated chitinase activity occurring when C3 was supplied with chitin could have been due in part to host chitinase production stimulated by chitin hydrolysis by C3. Western blot techniques using antibodies specific to bacterial chitinases or plant chitinases might be useful in answering the question as to the chitinase source.

We do not consider chitinolysis to be the sole mechanism by which strain C3 can affect B. sorokiniana and leaf spot development. Protease was an important factor in inhibition of Pythium ultimum by a rhizosphere strain of Stenotrophomonas maltophilia (5). Maltophilin, an antibiotic with antifungal activity, was reported from another rhizosphere strain (7), and xanthobaccins were implicated in the suppression of Pythium damping-off disease of sugar beet by a strain of Stenotrophomonas sp. (17). In this study, strain C3 excreted $\beta$-1,3-glucanase, protease, and lipase in vitro. Antifungal activity of culture fluid fractions, in general, was related to chitinase activity level, but fractions rendered nonchitinolytic and low molecular-weight components also had some degree of fungal

TABLE 4. Chitinase activity and population sizes detected in extracts of tall fescue leaves colonized by wild-type Stenotrophomonas maltophilia strain C3 and a chitinase-deficient mutant (7-41) with and without chitin and effects of leaf extracts on germination of conidia of Bipolaris sorokiniana in vitro $^{\mathrm{v}}$

\begin{tabular}{|c|c|c|c|}
\hline Treatment $^{\mathrm{w}}$ & $\begin{array}{c}\text { Chitinase units/ } \\
\mathrm{g} \text { of leaf }\end{array}$ & $\begin{array}{c}\text { Log CFU/ } \\
\text { g of leaf }\end{array}$ & $\begin{array}{c}\text { Conidial } \\
\text { germination }(\%)^{\mathrm{z}}\end{array}$ \\
\hline Phosphate buffer & $7.1 \mathrm{~d}$ & 0.00 & $86 \mathrm{a}$ \\
\hline Chitin & $8.6 \mathrm{c}, \mathrm{d}$ & 0.00 & $83 \mathrm{a}$ \\
\hline Strain 7-41 & $10.4 \mathrm{c}, \mathrm{d}$ & $7.19 \mathrm{~b}$ & $82 \mathrm{a}$ \\
\hline Strain $7-41+$ chitin & $11.6 \mathrm{c}$ & $7.16 \mathrm{~b}$ & $79 \mathrm{a}$ \\
\hline Strain C3 & $19.3 \mathrm{~b}$ & $8.04 \mathrm{a}$ & $66 \mathrm{~b}$ \\
\hline Strain C3 + chitin & $41.6 \mathrm{a}$ & $8.08 \mathrm{a}$ & $41 \mathrm{c}$ \\
\hline
\end{tabular}

v Extracts in phosphate buffer were made from leaves collected 4 days after treatments were applied to tall fescue plants. Values in a column followed by the same letter are not significantly different $(P=0.05)$ according to Duncan's multiple range test.

${ }^{w}$ All treatments were suspended in phosphate buffer and applied to tall fescue leaves.

${ }^{x}$ Chitinase activity was measured by hydrolysis of $p$-nitrophenyl- $N, N$-diacetylchitobiose. Values are means of two experiments with three replications each.

y $\mathrm{C} 3$ and 7-41 were applied to tall fescue plants to $\approx 7.5 \mathrm{log} \mathrm{CFU} / \mathrm{g}$ of leaf. Results from phosphate buffer and chitin treatments were not included in statistical analysis. Values are means of two experiments with three replications each.

${ }^{\mathrm{z}}$ Germination of conidia was determined after incubation for $20 \mathrm{~h}$ in extracts. Values are means of two experiments with three replications each. 
inhibition. The chitin-affinity chromatography fraction containing only chitin-binding proteins was highly chitinolytic but was not as inhibitory as the raw culture fluid, which also points to the involvement of multiple factors. Finally, the mutant strains deficient in chitinase activity retained some in vivo antifungal activity. Therefore, it is possible that $\mathrm{C} 3$ chitinases act synergistically with other lytic enzymes and antibiotic factors, as reported for Trichoderma hazianum (23). Confirmation of other mechanisms will require further investigation, but the involvement of multiple traits could have contributed to the consistent biocontrol of leaf spot by $\mathrm{C} 3$ we observed over a wide range of controlled and field conditions (32). In preliminary studies, strain C3 inhibited diseases caused by P. ultimum (G. Yuen, unpublished data), Botrytis cinerea (29), and Uromyces appendiculatus (28). The potential for multiple modes of action could be important in using strain $\mathrm{C} 3$ in controlling these other pathogens as well.

\section{ACKNOWLEDGMENTS}

University of Nebraska, Agricultural Research Division, Journal Series 12464. This research was part of NC-125 Regional Project (Biocontrol of Soilborne Pathogens) and also was supported in part by grants from the University of Nebraska Research Council and the Layman Foundation. We thank D. Kobayashi, Rutgers University, and G. Sarath, University of Nebraska-Lincoln, for providing valuable advise and discussions, and M. Craig and T. Rye for providing technical assistance.

\section{LITERATURE CITED}

1. Benhamou, N., and Chet, I. 1992. Hyphal interactions between Trichoderma harzianum and Rhizoctonia solani: Ultrastructure and gold cytochemistry of the mycoparasitic process. Phytopathology 83:1062-1071.

2. Bradford, M. M. 1976. A rapid and sensitive method for the quantitation of microgram quantities of protein utilizing the principle of protein-dye binding. Anal. Biochem. 72:248-254.

3. Chancey, S. T., Wood. D. W., and Pierson III, L. S. 1999. Two component transcriptional regulation of $N$-acyl-homoserine lactone production in Pseudomonas aureofaciens. Appl. Environ. Microbiol. 65:2294-2299.

4. Chernin, L., Ismailov, Z., Haran, S., and Chet, I. 1995. Chitinolytic Enterobacter agglomerans antagonistic to fungal plant pathogens. Appl. Environ. Microbiol. 61:1720-1726.

5. Dunne, C., Crowley, J. J., Moenne-Loccoz, Y., Dowling, D. N., de Bruijn, F. J., and O'Gara, F. 1997. Biological control of Pythium ultimum by Stenotrophomonas maltophilia W81 is mediated by an extracellular proteolytic activity. Microbiology 143:3921-3931.

6. Giesler, L. J., and Yuen, G. Y. 1998. Evaluation of Stenotrophomonas maltophilia strain $\mathrm{C} 3$ for biocontrol of brown patch disease. Crop Prot. 17:509-513.

7. Jakobi, M., and Winkelmann, G. 1996. Maltophilin, a new antifungal compound produced by Stenotrophomonas maltophilia R3089. J. Antibiot. (Tokyo) 49:1101-1104

8. Know, O. C. H., Fahy, P. C., Hoitink, H. A. J., and Kuter, G. A. 1987. Interactions between bacteria and Trichoderma hamatum in suppression of Rhizoctonia damping-off in bark compost media. Phytopathology 77:1206-1212.

9. Kobayashi, D. Y., Gugliemoni, M., and Clarke, B. B. 1995. Isolation of the chitinolytic bacteria Xanthomonas maltophilia and Serratia marcescens as biological control agents for summer patch disease of turfgrass. Soil Biol. Biochem. 27:1479-1487.

10. Kody, S., Schickler, H., Chet, I., and Oppenheim, A. B. 1994. The chitinase encoding Tn7-based ChiA gene endows Pseudomonas fluorescens with the capacity to control plant pathogens in soil. Gene 147:8183.

11. Kokalis-Burelle, N., Backman, P. A., Rodriguez-Kabana, R., and Ploper, L. O. 1992. Potential for biological control of early leaf spot of peanut using Bacillus cereus and chitin foliar amendments. Bio. Control 2:321-328.
12. Kritizman, G., Chet, I., Henis, Y., and Huttermann, A. 1978. The use of the brightener "Calcofluor White M2R New" in the study of fungal growth. Isr. J. Bot. 27:138-146.

13. Laville, J., Voisard, C., Keel, C., Maurhofer, M., Defago, G., and Haas, D. 1992. Global control in Pseudomonas fluorescens mediating antibiotic synthesis and suppression of black root rot of tobacco. Proc. Natl. Acad. Sci. USA 89:1562-1566.

14. Lorito, M., Harman, G. E., Hayers, C. K., Broadway, R. M., Tronsmo, A., Woo, S. L., and Di Pietro, A. 1993. Chitinolytic enzymes produced by Trichoderma harzianum: Antifungal activity of purified endochitinase and chitobiosidase. Phytopathology 83:302-307.

15. Molano, J., Duran, A., and Cabib, E. 1977. A rapid and sensitive assay for chitinase using tritiated chitin. Anal. Biochem. 83:648-656.

16. Monreal, J., and Reese, E. T. 1969. The chitinase of Serratia marcescens. Can. J. Microbiol. 15:689-696.

17. Nakayama. T., Homma, Y., Hashidoko, Y., Mizutani, J., and Tahara, S. 1999. Possible role of xanthobaccins produced by Stenotrophomonas sp. strain SB-K88 in suppression of sugar beet damping-off disease. Appl. Environ. Microbiol. 65:4334-4339.

18. Ordentlich, A., Elad, Y., and Chet, I. 1988. The role of chitinase produced by Serratia marcescens in biological control of Sclerotium rolfsii. Phytopathology 78:84-88.

19. Palleroni, N. J., and Bradbury, J. F. 1993. Stenotrophomonas, a new bacterial genus for Xanthomonas maltophilia (Hugh 1980) Swings et al. 1983. Int. J. Syst. Bacteriol. 43:606-609.

20. Roberts, W. K., and Selitrennikoff, C. P. 1988. Plant and bacterial chitinases differ in antifungal activity. J. Gen. Microbiol. 134:169-176.

21. Roby, D., Gadelle, A., and Toppan, A. 1987. Chitin oligosaccharide as elicitors of chitinase activity in melon plants. Biochem. Biophys. Res. Commun. 143:885-892.

22. Rodriguez-Kabana, R., Godoy, R., Morgan-Jones, G., and Shelby, R. A. 1983. The determination of soil chitinase activity: Conditions for assay and ecological study. Plant Soil 75:95-106.

23. Schirmbock, M., Lorito, M., Wang, Y., Hayes, C. K., Arisan-Atac, I., Scala, F., Harman, G. E., and Kubicek, C. P. 1994. Parallel formation and synergism of hydrolytic enzymes and peptaibol antibiotic action of Trichoderma harzianum against phytopathogenic fungi. Appl. Environ. Microbiol. 60:4364-4370.

24. Shapira, R., Ordentlich, A., Chet, I., and Oppenheim, A. B. 1989. Control of plant diseases by chitinase expressed from cloned DNA in $E s$ cherichia coli. Phytopathology 83:857-863.

25. Smeltzer, M. S., Hart, M. E., and Iandolo, J. J. 1992. A quantitative assay for lipase activity. Appl. Environ. Microbiol. 58:2815-2819.

26. Sundheim, L., Poplawsky, A. R., and Ellingboe, A. H. 1988. Molecular cloning of two chitinase genes from Serratia marcescens and their expression in Pseudomonas species. Physiol. Mol. Plant Pathol. 33:483491.

27. Whooley, M. A., O'Callaghan, J. A., and McLoughlin, A. J. 1983. Effect of substrate on the regulation of exoprotease production by Pseudomonas aeruginosa ATCC 10145. J. Gen. Microbiol. 129:981-988.

28. Yuen, G. Y., Kerr, E. D., Steadman, J. R., Lindgren, D. T., and Schaaf, D. 1998. Evaluations of bacteria and chitin for bean rust control. Biol. Cult. Tests 13:20.

29. Zhang, Z. 1999. Characterization of the Stenotrophomonas maltophilia C3 antagonism system against Bipolaris sorokiniana on tall fescue. $\mathrm{Ph} . \mathrm{D}$. dissertation. University of Nebraska, Lincoln.

30. Zhang, Z., and Yuen, G. Y. 1997. Chitinolytic properties of Stenotrophomonas maltophilia strain $\mathrm{C} 3$, an antagonist of fungal turfgrass pathogens (Abstr.). Phytopathology 87(suppl.):S109.

31. Zhang, Z., and Yuen, G. Y. 1999. Analysis of the role of chitinase in biological control of Stenotrophomonas maltophilia C3 using transposon mutants (Abstr.) Phytopathology 89(suppl.):S108.

32. Zhang, Z., and Yuen, G. Y. 1999. Biological control of Bipolaris sorokiniana on tall fescue by Stenotrophomonas maltophilia C3. Phytopathology 89:817-822.

33. Zhang, Z., Yuen, G. Y., Sarath, G., and Penheiter, A. 1998. Characterization of chitinases from a Stenotrophomonas maltophilia antagonist of fungal pathogens (Abstr.) Phytopathology 88(suppl.):S103.

34. Zheng, Y., and Wozniak, C. A. 1997. Adaptation of a $\beta-1,3$-glucanase assay to microplate format. BioTechniques 22:922-926. 